\title{
A Proposal for New Microclimate Indexes for the Evaluation of Indoor Air Quality in Museums
}

\author{
Eva Schito *, Daniele Testi and Walter Grassi \\ Department of Energy, Systems, Territory and Construction Engineering, University of Pisa, \\ Largo Lucio Lazzarino, 56122 Pisa, Italy; daniele.testi@unipi.it (D.T.); walter.grassi@unipi.it (W.G.) \\ * Correspondence: eva.schito@for.unipi.it; Tel.: +39-050-221-7111
}

Academic Editor: David Arditi

Received: 22 August 2016; Accepted: 10 October 2016; Published: 15 October 2016

\begin{abstract}
A correct artwork preservation requires strict values of several microclimate parameters, in particular temperature, humidity, and light. In existing museums, the evaluation of the effectiveness of current building plant systems and management is essential to avoid artwork deterioration. In this work, we propose the use of five simple performance indexes that use monitored data to estimate the suitability of the whole museum system in the maintenance of benchmark values of temperature, humidity, and light. The new indexes also take into account microclimate daily span and spatial homogeneity, which can represent a criticality in the preservative process. We apply these new indexes to the results of a monitoring campaign in Palazzo Blu, a museum in Pisa, which lasted for almost four months during a temporary exhibition on Toulouse-Lautrec works. The indexes show a mainly acceptable instantaneous microclimate, but HVAC (Heating, Ventilating and Air Conditioning) system improvement is necessary to avoid high thermo-hygrometric daily span. This methodology is useful for the identification of microclimate criticalities and can help the cooperation between conservation experts and professionals giving hints to improve museum internal microclimate. In case ofalready optimal microclimate, these indexes can be useful in more complex analyses, including simulations of possible retrofit actions, keeping microclimate suitability as a constraint.
\end{abstract}

Keywords: indoor microclimate quality index; museum; monitoring campaign; HVAC system

\section{On Microclimate for Artwork Preservation}

Artworks need strict microclimate conditions to be preserved. Each typology of artwork (e.g., paper, frescoes, paintings, stones) needs specific microclimate conditions for their preservation; in general, typical environmental parameters to be controlled are:

- mean temperature $\left({ }^{\circ} \mathrm{C}\right)$;

- $\quad$ maximum daily and seasonal temperature difference $\left({ }^{\circ} \mathrm{C}\right)$;

- mean relative humidity (\%);

- maximum daily and seasonal relative humidity difference (\%);

- maximum allowed illuminance (lx).

For each type of artwork, standards suggest suitable microclimate intervals [1-3]; in some cases, however, if the artifact has been acclimatized to a particular historical climate environment, it is preferable to maintain these conditions instead of standard intervals, to avoid climatic shocks of the artwork [4,5]. Technical standard UNI 10829 [1] lists acceptable values for illuminance and optimal and acceptable ranges for temperature and relative humidity (in some cases, it is not possible to achieve, at the same time, visitor comfort and correct conditions for artwork preservation [6]). The presence of dust and gaseous pollutants and microbial and UV radiations can also threaten artwork integrity [7-9]. 
Technical standards [1] discuss the complexity of the degradation issue, depending on the reciprocal interaction among artworks and the whole microclimate set. The technical standard helps technicians, suggesting two ranges of temperature and relative humidity to be maintained: a strict range and a more tolerability range. If microclimate is in the strict range, degradation of artworks does not occur. If microclimate is in the tolerability range, degradation does not occur if temperature and relative humidity variations are not too wide or frequent. In any case, the appropriate set of microclimate parameters to be maintained should be stated by experts on the basis of the actual conservation status, to minimize preservation risks.

In the past centuries, several artworks were damaged by inappropriate indoor air conditions. One of the most famous cases of damaged artworks is Leonardo's Last Supper, in Milan, Italy. The used painting technique is highly sensitive to humidity: unfortunately, the painting was subject for centuries to large and frequent changes in temperature and relative humidity [10]. High values of relative humidity caused the deterioration of the paintings on the Scrovegni Chapel walls (in Padua, Italy) [11,12] and wooden objects in Rosslyn Chapel (in Edinburgh, UK) [13,14]. Several other examples of artworks damaged by inappropriate microclimate can be found in $[7,8]$.

\section{Existing Buildings as Museums}

Existing and historical buildings are often used, especially in the Mediterranean area, for artwork hosting and exhibition. Differently from new museums (which are designed for the specific exhibition purpose), the use of existing buildings as museums needs a deep analysis. Historical buildings are characterized by high-mass walls and limited glass surfaces. Consequently, the daily changes in temperature are straightened due to thermal inertia; moreover, superheating of surfaces due to natural light is limited and a better control of the artwork lighting is possible (for example, using ambient light instead of point light, or low-IR and low-UV bulbs). On the other hand, historical buildings are often characterized by surface or interstitial condensation and cannot passively cope with abrupt microclimate changes, for example due to a high number of visitors, thus requiring the installation of new technical equipment. However, as these buildings are often protected as "works of art" themselves, the installation and use of Heating, Ventilating and Air Conditioning (HVAC) systems is often a complex issue. In some cases, in the last century, simple heating solutions were installed, but the non-optimal design of these systems can also be responsible for inadequate microclimate (in particular spatial and temporal gradients of temperature and relative humidity) [15-19]. A series of European Projects [20-22] dealt with the retrofit actions of several existing museums to improve both internal air quality and energy efficiency. These projects show that solutions must be carefully chosen on the basis of the correlation between external climate, collections preservation state, building envelope characteristics and technical equipment: each museum hence represents a unique case [6]. The relationship between external climate change and preservation of historic buildings, including museums, was the object of the European Project "Climate for Culture" [23]. The project analyzed several existing buildings in Europe and Egypt, simulating the risk of conservation and the energy demand in case of changing external climate.

An Italian piece of research $[24,25]$ points out that more than $80 \%$ of museums in the province of Siena are equipped with heating systems and about $40 \%$ with both heating and cooling systems. In the province of Florence, instead, about $90 \%$ of the museums are placed in historical buildings and most of them have no HVAC system [26]. As a consequence, the maintenance of suitable microclimate in terms of temperature and relative humidity is linked to thermal inertia and infiltration and ventilation losses.

The monitoring of the parameters of interest in artwork conservation (temperature, relative humidity, and light) is a useful tool for the evaluation of the effectiveness of installed technologies. During the last two decades, monitoring campaigns have been carried out in several famous museums and historic buildings [27-31], finding criticalities in the building plant system that might lead to artwork deterioration or identifying the best strategies to improve microclimate. 


\section{The Need of Microclimate Suitability Indexes}

Several protocols [32,33] and methodologies [30,34-37] were proposed to evaluate the environmental suitability for artwork preservation. Some of them only focus on instantaneous microclimate, other ones highlight the importance of little microclimate variation on daily or seasonal basis. However, a procedure including new, simple and comprehensive indexes seems necessary, to take into account the whole set of parameters that affect artwork conservation, verify the suitability of the current building plant system, and identify criticalities and possible solutions to improve the maintenance of optimal microclimate.

\subsection{A Proposal for New Microclimate Suitability Indexes}

Performance Index (P.I.), defined in [34], is the percentage of time in which temperature and relative humidity values (in a significant point of the hall) are within the strict range reported in [1]. P.I. is a single effective index in highlighting the microclimate criticalities in terms of temperature and relative humidity, especially if the index is plotted in a graph like the one in Figure 1. In graphs like this, each marker represents a monitoring acquisition and the solid lines identify the optimal microclimate area. The representation of different conditions during the monitoring campaign with different colors or markers (e.g., the data acquired during the opening hours of the museum in red and during the closing hours in blue) can be a good practice to help experts in conservation identify critical periods.

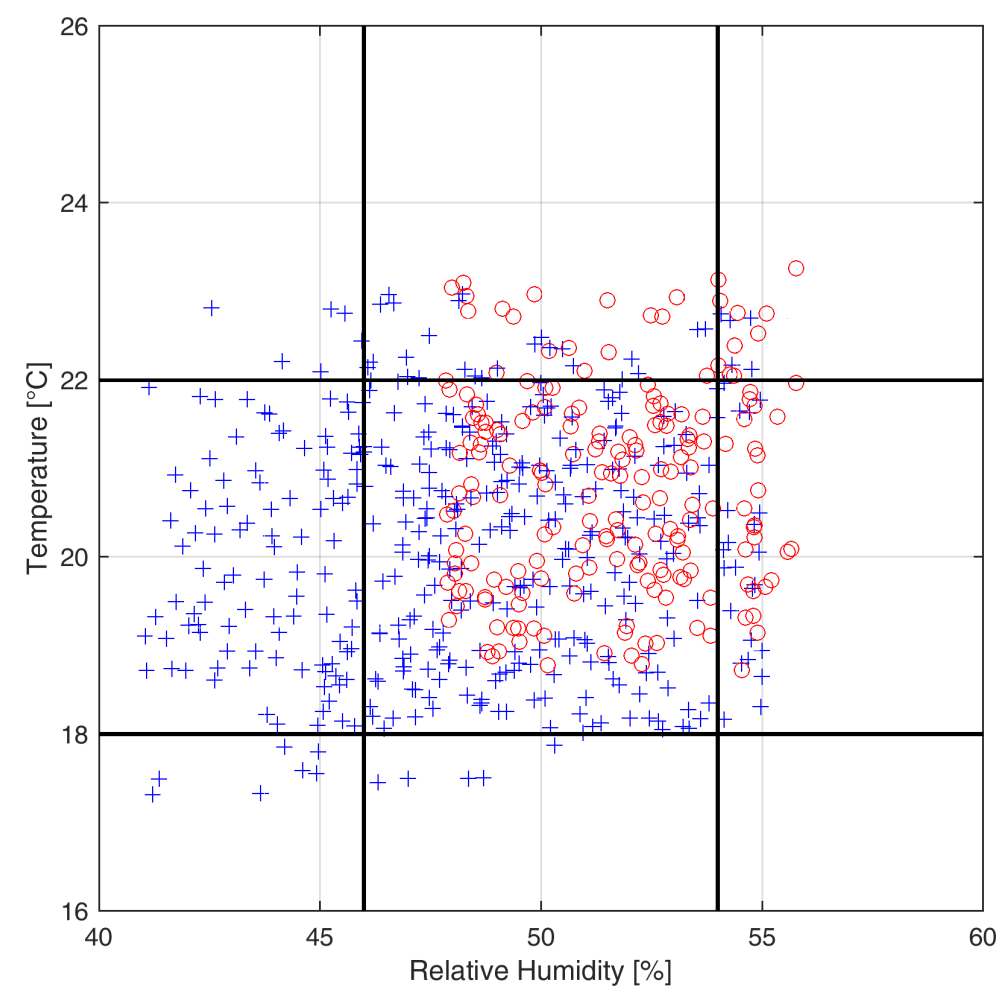

Figure 1. Example of graphical representation of P.I. Red markers identify data acquired during museum opening hours, while blue markers identify closing hours data.

However, instantaneous values of temperature and relative humidity in suggested ranges are not the only important parameters in artifacts preservation. As reported in Section 1, technical standards identify other parameters to be controlled: 
- maximum allowed illuminance, an important parameter, especially in the case of organic materials;

- daily variation of temperature and relative humidity: even if microclimate is maintained in suggested ranges, temperature and relative humidity can significantly vary on a daily basis and these cycles can cause artwork deterioration [38];

- spatial homogeneity of microclimate parameters: as reported in [1], the measuring points virtual grid has to be tightened in case of significant spatial microclimate variation.

Performance Index, as defined in [34], can be usefully applied in any environment that requires strict microclimate control, but new performance indexes specifically tailored to museum requirements should also take into account all the involved parameters in artifact preservation. Similarly to the Performance Index in [34], we propose four additional indexes that conservation experts can use to evaluate the effectiveness of the museum HVAC plant in maintaining the desired microclimate, according to the mentioned literature and standards:

- Performance Index related to the wider range (P.I.*), which identifies the percentage of time in which microclimate-in terms of temperature and relative humidity-occurs in the monitored environment remaining within the more tolerant range;

- Light Suitability Index (L.S.I.), which identifies the percentage of time in which illuminance does not exceed the maximum allowed limit;

- Daily Span Index (D.S.I.), which identifies the percentage of days in which the maximum values of temperature and relative humidity span do not exceed the allowed limits;

- Spatial Homogeneity Index (S.H.I.), which identifies the percentage of time in which microclimate is sufficiently homogeneous in the defined volume, according to the allowed spatial variations.

It is left to conservation experts to choose the most appropriate microclimate set to be considered as benchmark conditions for the preservation of the specific exposed artworks.

\subsection{Importance of the Application of the New Methodology}

As reported in Section 1, it is not possible to correlate index values with a specific damage probability; however, the use of this procedure can highlight the ability for the whole building plant system to reach the suggested microclimate intervals. The proposed methodology is usually easily implementable if the museum is already provided with monitoring sensors. According to [1], sensors should be placed in significant spatial points and the monitoring campaign should last for the necessary time period to identify temporal profiles of the main microclimate parameters ([1], at least one month per season is suggested). The data acquisition frequency should be chosen to record the rapid changes in temperature and relative humidity due to internal gains (e.g., $15 \mathrm{~min}$ ). The method application can provide relevant information on the museum microclimate suitability and give hints on a better management of all the systems in a museum. At the same time, it is obvious that a detailed knowledge of the whole system is necessary for the correct procedure application, as several different causes can result in the same effects on microclimate. For example, a low value of S.H.I. can reveal presence of punctual sources or sinks of heat or moisture, or a poor air circulation, which can be improved with a change in the Air Handling Unit (AHU) or fancoil damper position, if possible. A low value of P.I. or P.I.* can be caused by undersizing of the generators or heat exchangers in the AHU or inadequate choice of control parameters (e.g., supply air set-points, switching-on periods of the HVAC system): the analysis of a graphical representation of the indexes can help in the identification of the problem that causes low-quality microclimate. Figure 1, for example, shows a high number of acquisitions characterized by acceptable temperature but undesirable relative humidity during nights. This can be ascribed to the utilization of heating system during nights, while the ventilation system is switched off: a possible solution can be the use of humidifiers or the use of AHU for a few hours before the museum opening (when circulation between the halls and effects of moisture penetration in walls cause the lowest relative humidity values). Finally, a low value of L.S.I. can suggest the need of more diffused lighting. These indexes can be useful in museums housed in existing buildings, as the design 
of technical equipment is usually non-optimal. In any case, this methodology can be also applied in new museums, to verify the effectiveness of the whole system. Another useful application can be the comparison of different retrofit solutions in museums that already have suitable microclimate, aimed at improving other aspects (e.g., visitor comfort, energy efficiency), using physical models of the building plant system, such as in [39,40].

Several pieces of research report multi-objective analysis of museums: these studies aim to identify retrofit actions to reduce energy demand or enhance thermal comfort, the maintenance or improvement of indoor microclimate being constraints [41-43].

Figure 2 shows a possible application of the indexes in case of retrofit action choice. Experts in conservation define benchmark values for the five indexes; several solutions are tested, comparing the indexes values from simulation with benchmark values, thus identifying the best retrofit action to apply.

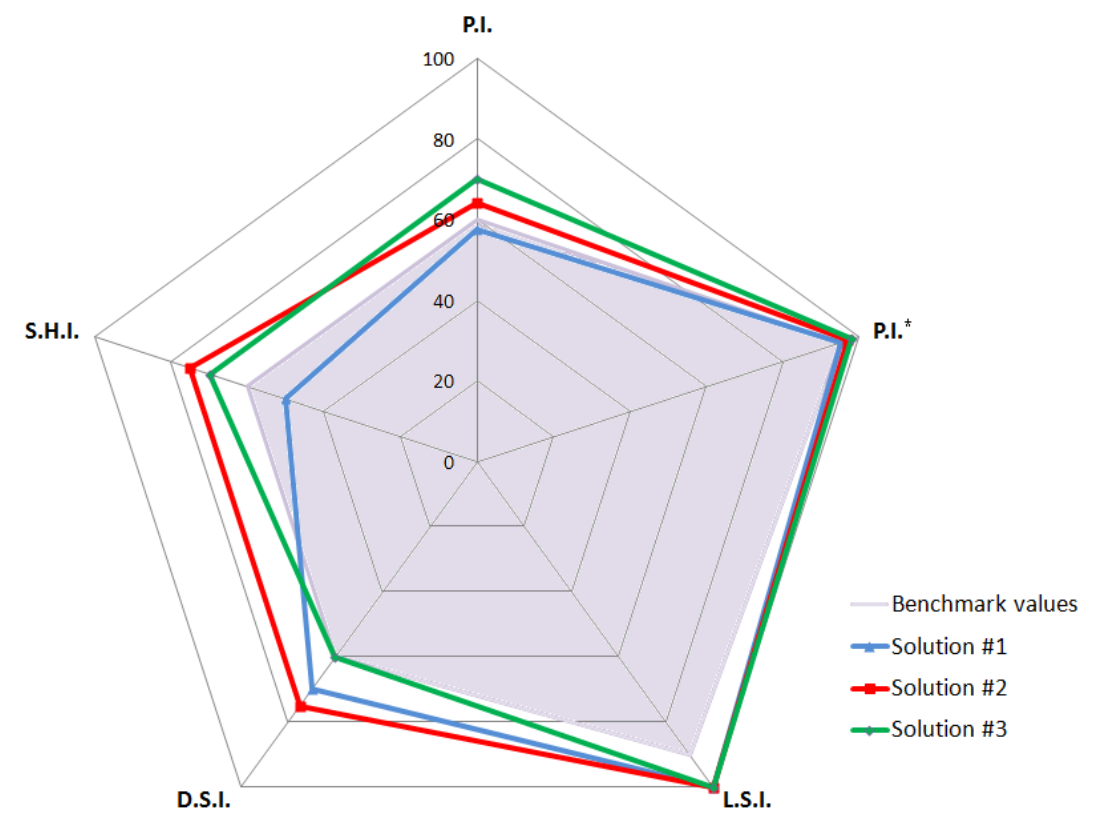

Figure 2. Example of application of the proposed procedure in the case of simulation of several retrofit actions.

\section{A Practical Application}

We applied the proposed methodology starting a monitoring campaign in Palazzo Blu, an important museum in Pisa. The monitoring campaign took place for almost four months, the whole period of a temporary exhibition on Toulouse-Lautrec's drawings. According to UNI 10829 [1], the reference microclimate for an optimal preservation of this type of artworks is the following:

- internal temperature between $18{ }^{\circ} \mathrm{C}$ and $22^{\circ} \mathrm{C}$ (temperature is still considered acceptable between $16.5^{\circ} \mathrm{C}$ and $23.5^{\circ} \mathrm{C}$ );

- internal relative humidity between $40 \%$ and $55 \%$ (relative humidity is still considered acceptable between $34 \%$ and $61 \%$ );

- maximum allowed illuminance up to $50 \mathrm{~lx}$.

In the following sections, we present a brief description of the museum and of the installed sensors, and we discuss the results of the monitoring campaign on the basis of the proposed procedure.

\subsection{Description of Palazzo Blu and of the Monitored Rooms}

Palazzo Blu is a museum located in the center of Pisa, alongside the Arno River. The museum hosts two permanent exhibitions and two temporary exhibitions (a "winter" and a "summer" exhibition) 
every year. Strict microclimate control is necessary for the correct preservation of the high cultural value of the exposed artworks: thus, a complex system is used, including:

- an AHU, which provides fresh air from 8 a.m. to 9 p.m. every day, containing filters, two heating elements, a cooling element, a vaporizer, and a blower; the air flow rate is $2800 \mathrm{~m}^{3} / \mathrm{h}$ and the set-point supply temperature is $18^{\circ} \mathrm{C}$;

- an air-to-water heat pump, which provides alternatively heating or cooling, with fan coils as emitting system; this system is switched on from 7 a.m. to 10 p.m.;

- a management system measures temperature and relative humidity in the rooms, controlling the HVAC system to maintain the chosen set points and coping with the abrupt variations of microclimate due to internal loads (i.e., visitors).

The last temporary exhibition took place from 17 October 2015, to 14 February 2016: more than 180 artworks by Henri de Toulouse-Lautrec were displayed. During this period, the museum was open every day, from 10 a.m. to 7 p.m. (from Monday to Friday) or from 10 a.m. to 8 p.m. (on Saturdays and Sundays). Almost 90,000 people visited Palazzo Blu during the 122 days of exhibition period, with an average daily number of 700 visitors and up to 2000 during weekends. The daily trend of tickets sold shows afternoon peaks. In accordance with the curators, four rooms of this zone were selected for a monitoring campaign: these rooms hosted the most famous exposed works by Toulouse-Lautrec. However, in the following sections, we will present the analysis of the two adjacent rooms on the first floor (Reference Rooms, RRs) with the highest presence of visitors, due to the relevance of the exposed artworks: their volume is about $340 \mathrm{~m}^{3}(8.5 \mathrm{~m}$ by $10 \mathrm{~m}$, height: $4 \mathrm{~m})$. These rooms are characterized by masonry external walls (average total thickness: $70 \mathrm{~cm}$, thermal transmittance: $0.9 \frac{\mathrm{W}}{\mathrm{m}^{2} \mathrm{~K}}$ ) and no glazed area.

\subsection{Position and Characteristics of the Installed Sensors}

The monitoring campaign in the two RRs was carried out using the following sensors:

- two SIEMENS DESIGO sensors (SIEMENS AG, Berlin and Munich, Germany), which acquire temperature to control the technical equipment through the management system (mean temperature accuracy: $\pm 0.7 \mathrm{~K}$, mean relative humidity accuracy: $\pm 3 \%$ );

- two 4-noks ZED-THL-M sensors (4-NOKS, Mossa, Gorizia, Italy), which acquire data on temperature, relative humidity, and illuminance (mean temperature accuracy: $\pm 0.2 \mathrm{~K}$, mean relative humidity accuracy: $\pm 3 \%$;

- two pair of SEMITEC NTC 103AT-2 sensors (SEMITEC Corporation, Tokyo, Japan), each acquiring temperature at two different heights of the hall, $1.5 \mathrm{~m}$ and $2.5 \mathrm{~m}$ height (mean temperature accuracy: $\pm 0.2 \mathrm{~K}$, mean relative humidity accuracy: $\pm 3 \%$ ).

An analogous set of sensors was positioned in the other two monitored rooms on the ground floor and additional temperature data were collected from the AHU dampers and from the rooms adjacent to the monitored ones. DESIGO sensors collect data every $15 \mathrm{~min}$, while SEMITEC and 4-nok sensors acquire the signal every $6 \mathrm{~min}$. A linear interpolation was used to estimate acquisition data within a 15 min time step instead of a 6 min time step, thus allowing synchronization and comparison of the data acquired by the different sensors.

The data-gathering lasted for the whole exhibition period and data were automatically saved and available on a wireless network, allowing remote check and download. More detailed information on the monitoring system is reported in Appendix A.

\subsection{Main Results of the Monitoring Campaign}

The monitoring campaign showed that, even if an acceptable microclimate occurs most of the time, there is room for improvement of microclimate conditions. Figure 3 shows the mean values of temperature and relative humidity in RRs during the whole monitored period: each marker identifies 
an acquisition, recorded every 6 min (about 30,000 total data points). The red cross markers identify the data referring to the opening hours of the museum, while the blue circle markers identify the data related to the closing hours. The black rectangle identifies the optimal microclimate for preservation, while the larger cyan rectangle identifies the acceptable microclimate. It can be noted that the highest values of relative humidity and temperature are recorded at the opening hours of the exhibition (when the presence of visitors most influences internal microclimate): in fact, the mean values of temperature and relative humidity during the opening hours are, respectively, $21.0^{\circ} \mathrm{C}$ and $51.2 \%$, while the same values monitored during the closing hours are, respectively, $20.3{ }^{\circ} \mathrm{C}$ and $49.5 \%$.

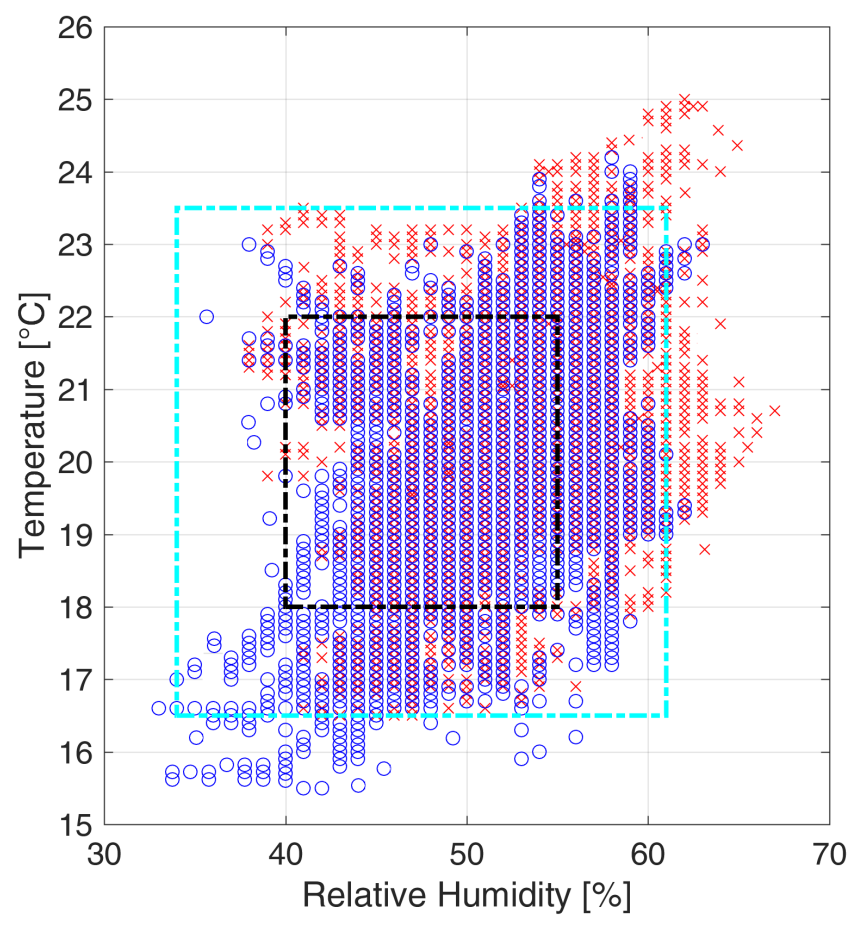

Figure 3. Monitored values of temperature and relative humidity in the RR. Red cross markers identify data collected during the museum opening hours, while blue circle markers identify data collected during closing hours.

On the basis of the monitored data, we calculated the value of P.I. (65\%), P.I.* $(98 \%)$ and L.S.I. (100\%). These values well highlight the suitability of the HVAC system in maintaining a microclimate that does not cause deterioration of the artworks and a correct design of the artificial lighting (mean illuminance value: $15 \mathrm{~lx}$ ). In Figure 4, the daily span of temperature and relative humidity in the RRs is shown: the blue star markers identify the data referring to weekdays, while the red circle markers identify data referring to weekends. The gray area identifies the suggested maximum values of microclimate span, according to [38]. On the basis of these monitored data, we calculated the D.S.I., which is $48 \%$. The D.S.I. value highlights a criticality in the RRs: the daily span of temperature and relative humidity is particularly high during weekends. This can be ascribed to the absence of dehumidification in the AHU components. In fact, chilled coils cannot be employed because, during winter, the heat pump can provide only hot water; however, especially during weekends, dehumidification coils are needed due to the high number of visitors. In any case, the high thermal inertia of the envelope is useful in reducing the temperature gap in the daily cycle, as the HVAC system is switched off during the night. The positive effect of the high mass walls is shown in Figure 5, where external and internal temperature are compared for a reference week (from 14 to 20 December). Internal temperature does not show relevant variation on a daily cycle. 


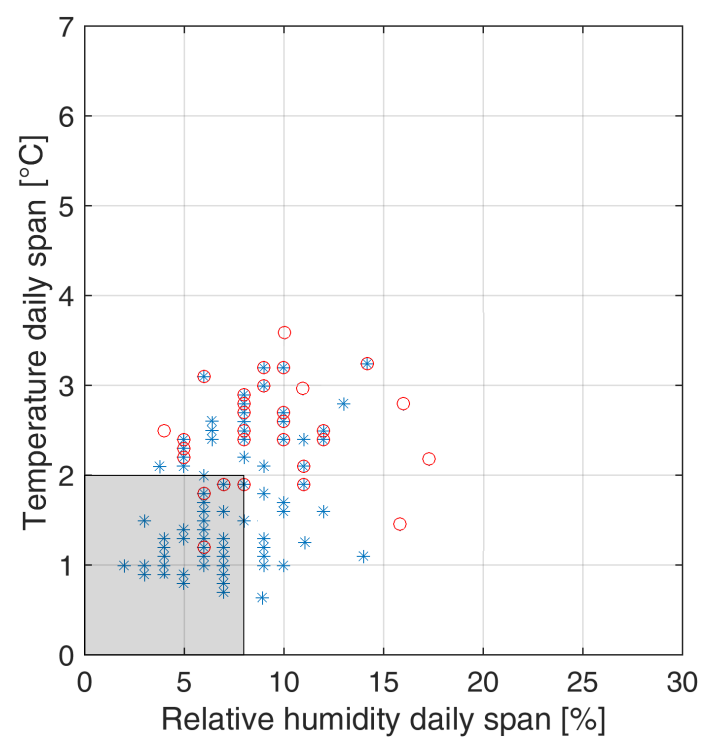

Figure 4. Daily variation of temperature and relative humidity in the RRs. Each marker identifies the variation of temperature and relative humidity during an exhibition day (122 monitored days). Blue markers identify weekdays, red markers identify weekends. The gray area represents the suggested maximum daily span for the two microclimate parameters to preserve artworks.

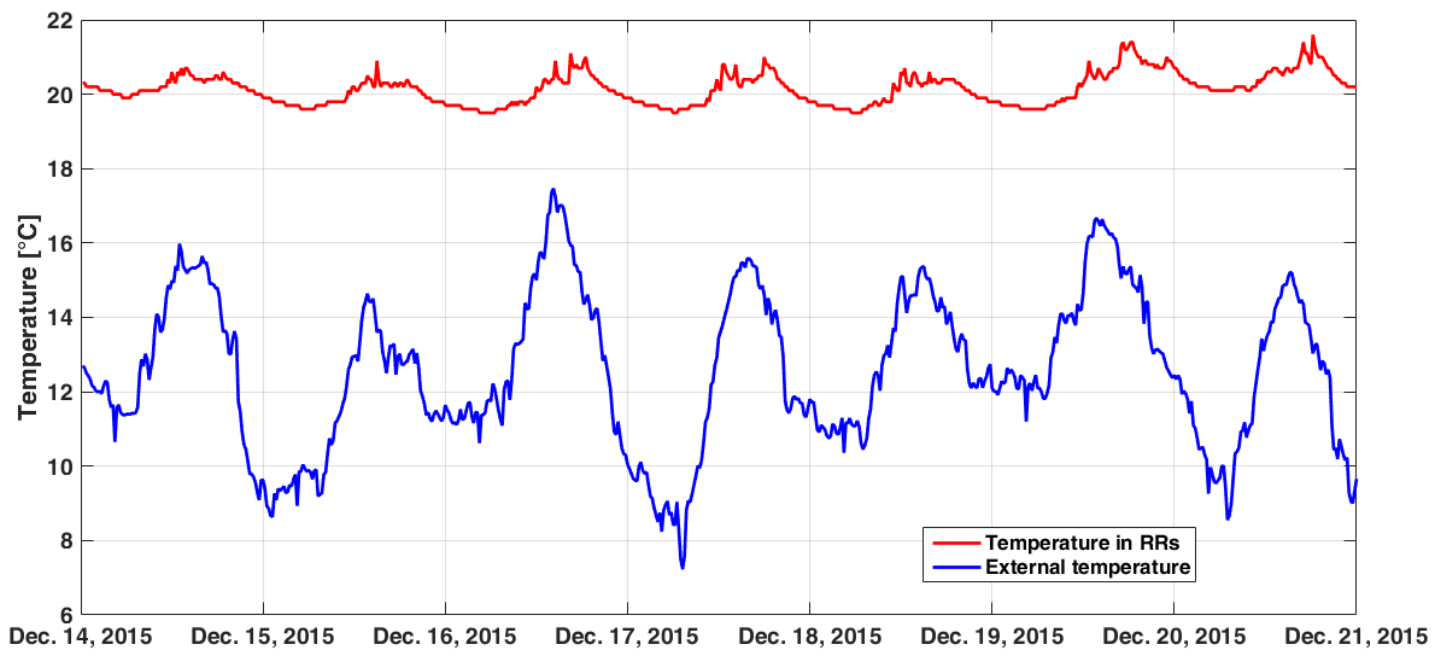

Figure 5. Internal and external temperature on a reference week. Thermal inertia reduces the effects of a wide temperature gap between days and nights.

For the evaluation of the S.H.I., we referred to the perimeter of the RRs. We measured the maximum span of temperature and relative humidity along the perimeter of the rooms in December. The resulting value of S.H.I. is $74 \%$. Figure 6 represents the spatial span, with the gray area representing the suggested values for spatial homogeneity as reported in [1]. Blue star markers identify the data referred to the closing hours of the museum, while red circle markers identify data referred to the opening hours. Figure 6 shows that unacceptable spatial temperature span occurs usually during the opening hours of the museum, while relative humidity can be considered homogeneous in space. It is worth noting that there is no inconsistency among the indexes values on relative humidity: this parameter sometimes exceeds the acceptable instantaneous limits and significantly changes on daily cycles, but instantaneously does not vary in space. 


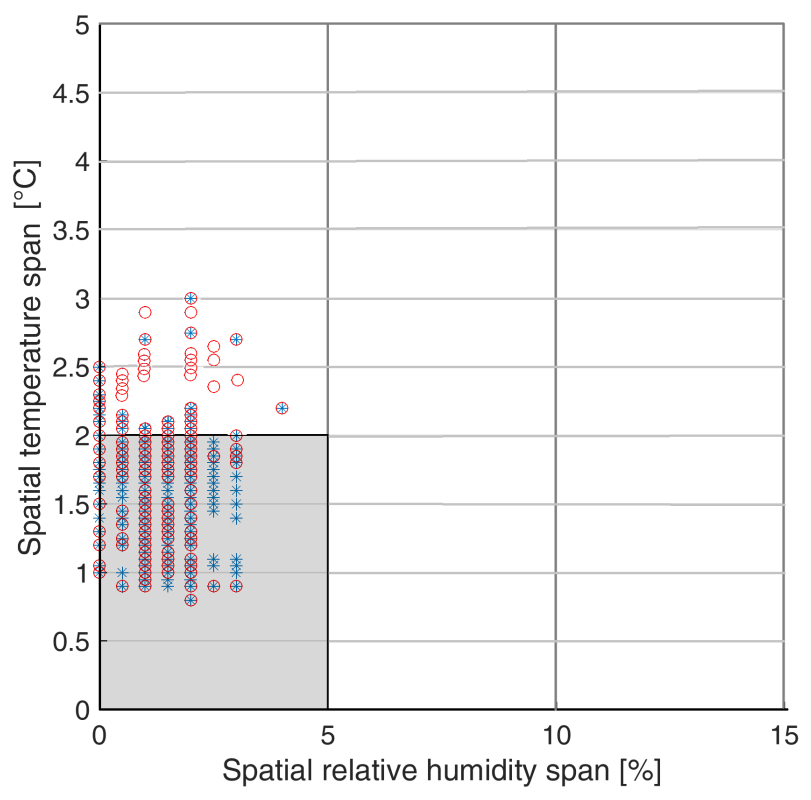

Figure 6. Representation of the spatial homogeneity of temperature and relative humidity. Red markers refer to data acquired during opening hours, blue markers identify data during closing hours. The gray area represents the suggested values for spatial homogeneity.

The presence of visitors strongly influences temperature and relative humidity in the halls: in particular, visitors are responsible for high relative humidity values on the opening hours, even if the monitoring campaign does not show relevant spatial variation of this parameter in the analyzed volume. On the contrary, temperature significantly varies along the perimeter. This effect is visible in Figure 7, displaying the internal temperature profile (monitored at a $1.5 \mathrm{~m}$ height) along the perimeter of the two rooms at the first floor, during a benchmark week (from 14 to 21 December). We report a parametrization of the perimeter of the two rooms with the blue line in Figure 8; the red rectangles represent the AHU dampers and the central black rectangles represent the fan coil units. In Figure 7, two higher-temperature areas are identified: the first is at $x$ values between 0 and $10 \mathrm{~m}$ along the perimeter, and the second is between 25 and $30 \mathrm{~m}$. The higher temperatures are due to internal heat gain caused by visitors that gather in the vicinity of the famous posters and artworks by Toulouse-Lautrec (for example, Reine de joie and La Passagere du 54), which attracted more visitors.

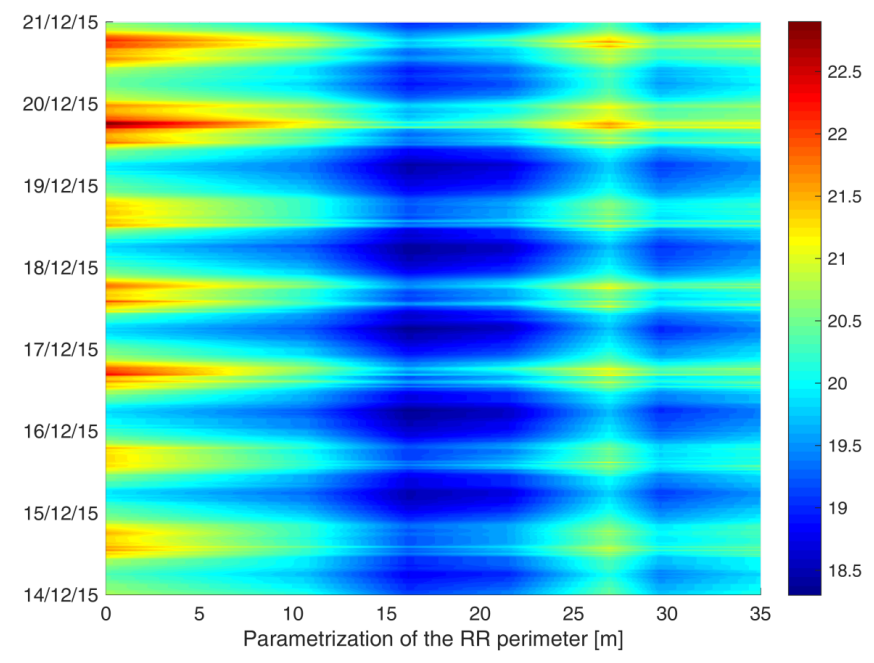

Figure 7. Space-temporal profile of temperature in the two rooms at the first floor. Point A of Figure 8 is at the origin of the $x$-axis, while point $\mathrm{B}$ is at $\mathrm{x}=35 \mathrm{~m}$. 


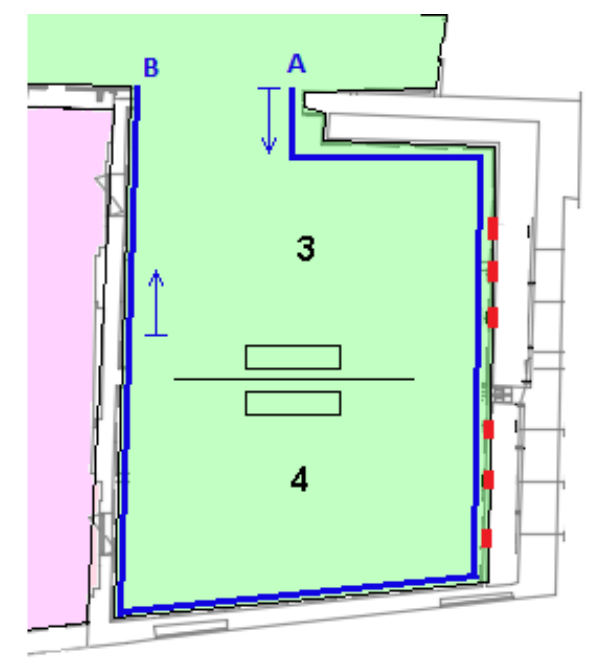

Figure 8. Parameterization of the perimeter of the RRs.

The typical heating due to visitors' presence is clearly visible on a daily basis, and it is more marked during the afternoon hours. It is worth noticing that, during the weekend, temperatures along the whole perimeter were higher, revealing a higher number of visitors. These results, highlighted by the monitoring campaign, are confirmed by the hourly profile of sold tickets during the benchmark week, as shown in Figure 9, which shows the average number of sold tickets during the benchmark week, differentiating a typical weekday from a weekend.

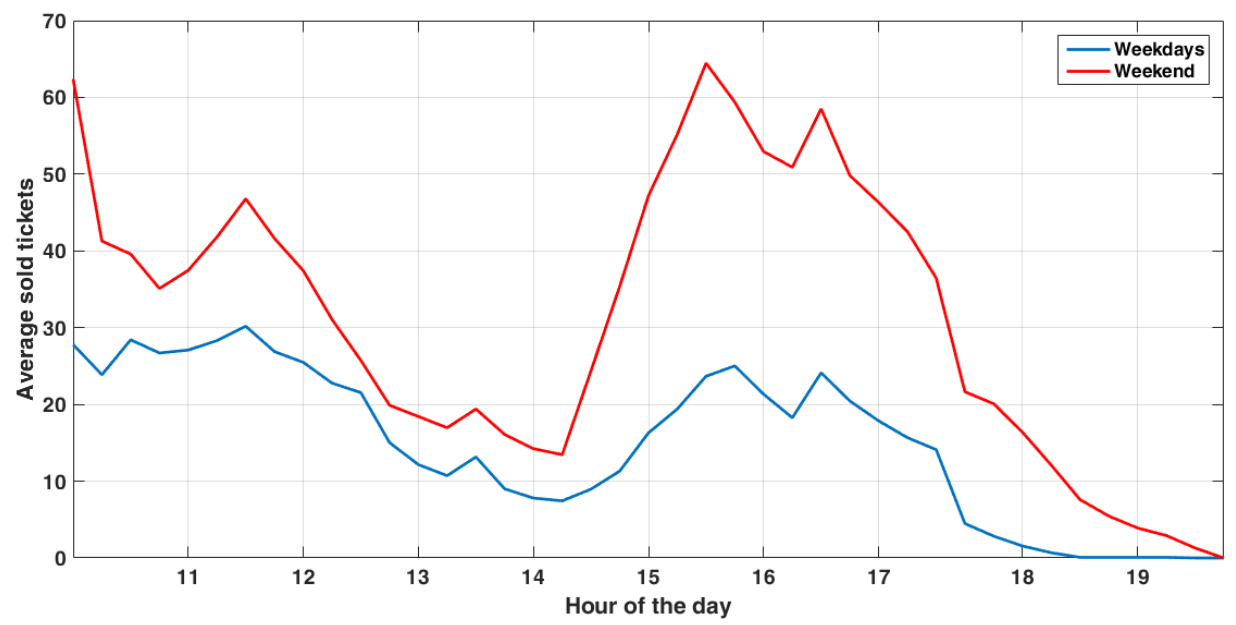

Figure 9. Number of visitors during the opening hours in the benchmark week.

The values of the proposed indexes for the monitored rooms are summarized in Table 1 and graphically represented in Figure 10. Indeed, these indexes are capable of showing, in a concise and effective fashion, the microclimate suitability of museum environments. In this particular case, as already discussed, they highlight that the HVAC system is effective in maintaining instantaneous suitable conditions for artwork preservation, but improvements are necessary to reduce the variation of microclimate parameters on daily cycles. 
Table 1. Values of the proposed indexes resulting from the monitoring campaign of the RRs.

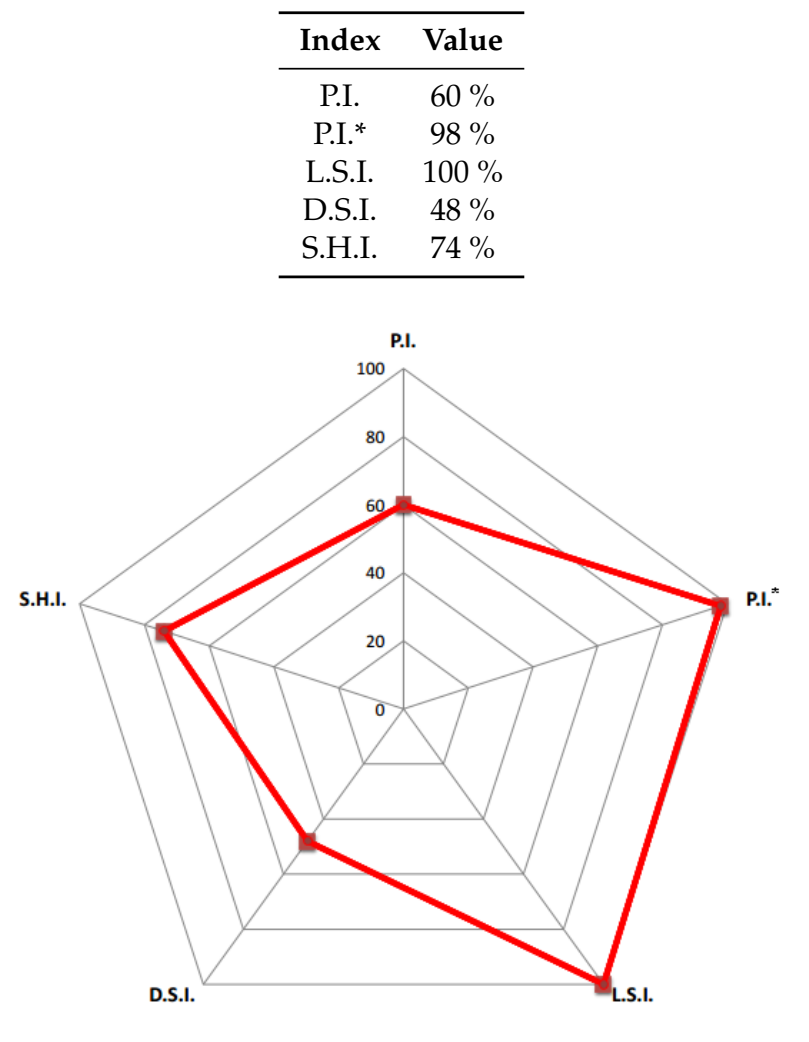

Figure 10. Representation of the five indexes on a radar plot.

\section{Conclusions}

In this work, we showed that new performance indexes are necessary to evaluate the microclimate suitability in museums, as the currently used index does not take into account the whole set of microclimatic parameters that are important in artwork preservation. The five indexes (one already defined and four new indexes) are easy to evaluate and they provide a comprehensive view of the museum microclimate: starting from a monitoring campaign, the indexes estimate the suitability of the lighting system and the effectiveness of the building's HVAC system in the maintenance of optimal range, acceptable range, daily span, and spatial homogeneity of internal temperature and humidity. These indexes can help in the identification of periods and zones where the internal microclimate is most influenced by external factors (e.g., visitor presence), which can potentially be critical for artwork preservation. The proposed methodology was applied carrying out a monitoring campaign of the four main rooms of Palazzo Blu, during a temporary exhibition. The analysis of the indexes revealed that the instantaneous current microclimate is mainly acceptable for artwork preservation, but the daily span should be reduced. In particular, relative humidity needs a stricter control, to cope with the high crowding of visitors, which would require dehumidifation of the air supply even during winter. This process is not possible at the moment, due to the configuration of the heat pump and AHU systems. This information can help the curators in the choice of correct actions in favor of preventive conservation: one could think of new crowding management (for example, imposing a maximum number of visitors present at the same time in the room, or limiting the stay in the room) or the concurrent use of heating and cooling coils of the AHU. The interaction between the building plant system and artwork preventive conservation is well-known and proved by several examples. The application of these simple indexes can highlight the typical criticalities that experts in conservation can encounter in their work and also suggest possible causes and retrofit actions to improve microclimate. Moreover, the methodology can be used in a more general 
framework, such as multi-objective analyses aimed at identifying optimized management strategies for concurrent achievement of different goals (for example, preventive conservation and visitor comfort or energy efficiency).

Acknowledgments: We gratefully acknowledge the Fondazione Palazzo Blu, in particular the President, Cosimo Bracci Torsi, and Riccardo Moschetti, for allowing us to conduct the microclimate monitoring campaign. We also want to thank our department technologist Davide Della Vista, for setting-up the wireless monitoring system.

Author Contributions: The paper summarizes a substantial part of Eva Schito's doctoral activities. Daniele Testi and Walter Grassi supervised all the phases of the research work.

Conflicts of Interest: The authors declare no conflict of interest.

\section{Abbreviations}

The following abbreviations are used in this manuscript:

$\begin{array}{ll}\text { AHU } & \text { Air Handling Unit } \\ \text { D.S.I. } & \text { Daily Span Index } \\ \text { HVAC } & \text { Heating, Ventilating and Air Conditioning } \\ \text { IR } & \text { Infrared } \\ \text { L.S.I. } & \text { Light Suitability Index } \\ \text { P.I. } & \text { Performance Index } \\ \text { P.I.* } & \text { Performance Index related to a wider range } \\ \text { RRs } & \text { Reference Rooms } \\ \text { S.H.I. } & \text { Spatial Homogeneity Index } \\ \text { UV } & \text { Ultraviolet }\end{array}$

\section{Appendix A. Description of the Monitoring System}

The four monitored rooms are provided with four SIEMENS DESIGO sensors, collecting data every $15 \mathrm{~min}$ on temperature and relative humidity values, thus controlling the technical equipment through the management system. For the specific purpose of the monitoring campaign, we also collected data from the adjacent rooms (to record the temperature values as boundary conditions), from the AHU dampers, and from the return duct to the heat pump. Then, we used additional sensors (4-nok sensors and SEMITEC sensors) in the rooms, to verify the spatial homogeneity of the environmental variables and the microclimate suitability in the artworks proximity: all these sensors acquired data every $6 \mathrm{~min}$. Another temperature and relative humidity sensor (DICKSON, Addison, IL, USA) was posed at the AHU inlet, acquiring data every $15 \mathrm{~min}$. DESIGO sensors send data to the management system, from which the download is possible. DICKSON sensor is provided with an internal flash memory, which allows data transfer. The other installed sensors are connected to the datalogger via a wireless network based on the ZigBee standard. Each node sends the sensor signal to a coordinator device that creates the network, maintains the wireless traffic among the sensors, and transfers data to the datalogger via Modbus (4-noks, AstreGroup, Mossa, Gorizia, Italy). The datalogger acts as a server, allowing remote control and data downloading. To increase the accuracy of the additional temperature sensors, calibration in an incubator (BINDER KB240 model, BINDER $\mathrm{GmbH}$, Tuttlingen, GERMANY) was performed prior to their installation: the temperature in the incubator was measured through a reference Pt100 resistance temperature detector (Minco S7933 model, MINCO Products, Minneapolis, MN, USA) and compared with the values measured by the additional temperature sensors in the range $5-40{ }^{\circ} \mathrm{C}$, revealing an accuracy of $\pm 0.2 \mathrm{~K}$ for 4-noks and SEMITEC sensors, and $\pm 0.2 \mathrm{~K}$ for the DICKSON sensor. We calculated the specific humidity uncertainty from the uncertainties of temperature and relative humidity sensors, with traditional propagation of error expressions $( \pm 0.1 \mathrm{~g} / \mathrm{kg}$ in the range $1.5-20 \mathrm{~g} / \mathrm{kg})[44]$. 
Tables A1 and A2 summarize the models and characteristics of all the monitoring sensors and Figure A1 shows the location of the ones placed in the rooms. In Tables A1 and A2, the acronyms T and R.H. refer to temperature and relative humidity, respectively.

Table A1. Specifics of the SIEMENS sensors.

\begin{tabular}{cccccc}
\hline Model & Position & $\begin{array}{c}\text { Monitored } \\
\text { Parameter }\end{array}$ & $\begin{array}{c}\text { Measuring } \\
\text { Range }\end{array}$ & Accuracy & $\begin{array}{c}\text { Acquisition } \\
\text { Period }\end{array}$ \\
\hline QFA2001 & Room no. 1 & $\mathrm{T}$ & $0 \ldots 50^{\circ} \mathrm{C}$ & $\begin{array}{c} \pm 0.7 \mathrm{~K} \text { in the } \\
\text { range } 15 \ldots 35^{\circ} \mathrm{C} \\
\pm 3 \% \text { in the } \\
\text { range } 0 \ldots 100 \%\end{array}$ & $15 \mathrm{~min}$ \\
\hline QAA24 & $\begin{array}{c}\text { Room no. 2 } \\
\text { Room no. 5 }\end{array}$ & $\mathrm{T}$ & $-50 \ldots+80^{\circ} \mathrm{C}$ & $\begin{array}{c} \pm 0.6 \mathrm{~K} \\
\text { in the range } \\
-5 \ldots 30^{\circ} \mathrm{C}\end{array}$ & $15 \mathrm{~min}$ \\
\hline QFM21160 & AHU dampers & $\mathrm{T}$ & $0 \ldots 50^{\circ} \mathrm{C}$ & $\begin{array}{c} \pm 0.7 \mathrm{~K} \text { in the } \\
\text { range } 15 \ldots 35^{\circ} \mathrm{C} \\
\pm 3 \% \text { in the } \\
\text { range } 0 \ldots 100 \%\end{array}$ & $15 \mathrm{~min}$ \\
\hline
\end{tabular}

Table A2. Specifics of the additional sensors.

\begin{tabular}{|c|c|c|c|c|c|}
\hline Model & Position & $\begin{array}{l}\text { Monitored } \\
\text { Parameter }\end{array}$ & $\begin{array}{l}\text { Measuring } \\
\text { Range }\end{array}$ & Accuracy & $\begin{array}{l}\text { Acquisition } \\
\text { Period }\end{array}$ \\
\hline $\begin{array}{l}\text { 4-noks } \\
\text { ZED-THL-M }\end{array}$ & $\begin{array}{l}\text { Room no. } 2 \\
\text { Rooms no. } 3 \text { and no. } 4\end{array}$ & $\begin{array}{l}\text { T } \\
\text { R.H. } \\
\text { I }\end{array}$ & $\begin{array}{c}-40 \ldots+120^{\circ} \mathrm{C} \\
0 \ldots 100 \% \\
0 \ldots 1000 \mathrm{~lx}\end{array}$ & $\begin{array}{l} \pm 0.2 \mathrm{~K} \text { in the } \\
\text { range } 5 \ldots 40{ }^{\circ} \mathrm{C} \\
\pm 3 \% \text { in the } \\
\text { range } 0 \ldots 100 \% \\
\quad \pm 5 \%\end{array}$ & $6 \mathrm{~min}$ \\
\hline $\begin{array}{l}\text { SEMITEC } \\
\text { NTC } \\
103 \mathrm{AT}-2\end{array}$ & $\begin{array}{l}\text { Rooms no. } 1 \text { and no. } 2 \\
\text { Rooms no. } 3 \text { and no. } 4 \\
\text { Room no. } 6\end{array}$ & $\mathrm{~T}$ & $-50 \ldots+110^{\circ} \mathrm{C}$ & $\begin{array}{c} \pm 0.2 \mathrm{~K} \\
\text { in the range } \\
5 \ldots 40^{\circ} \mathrm{C}\end{array}$ & $6 \mathrm{~min}$ \\
\hline $\begin{array}{l}\text { DICKSON } \\
\text { TM325 }\end{array}$ & AHU entrance & $\begin{array}{c}\text { T } \\
\text { R.H. }\end{array}$ & $\begin{array}{c}-20 \ldots+70{ }^{\circ} \mathrm{C} \\
0 \ldots 95 \%\end{array}$ & $\begin{array}{l} \pm 0.5 \mathrm{~K} \text { in the } \\
\text { range } 5 \ldots 40^{\circ} \mathrm{C} \\
\pm 3 \% \text { in the } \\
\text { range } 0 . .95 \%\end{array}$ & $15 \min$ \\
\hline
\end{tabular}

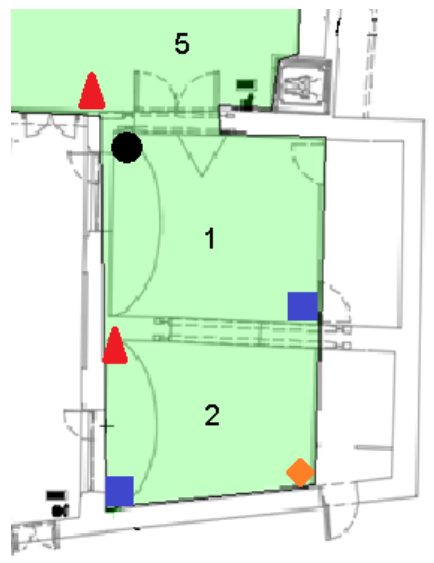

Ground floor

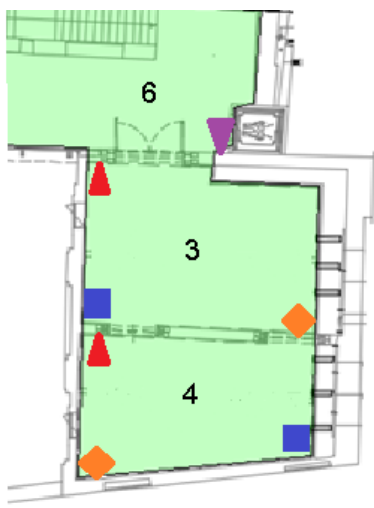

First floor

Figure A1. Sensor position in the four rooms. The round black marker identifies the QFA2001 sensor, the red triangle markers identify QAA24 sensors, the blue square markers identify 103AT-2 sensors (for the measure of temperature at $1.5 \mathrm{~m}$ and $2.5 \mathrm{~m}$ height), the orange diamond markers identify ZED-THL-M sensors, the inverted purple triangle marker identifies the 103AT-2 sensor for the measurement of temperature at $1.5 \mathrm{~m}$ height in the adjacent room. 


\section{References}

1. UNI 10829 Historical and Cultural Heritage. Environmental Conditions for Preservation; Ente Italiano di Unificazione: Milan, Italy, 1999. (In Italian)

2. ISO 18902 Imaging Materials_Processed Imaging Materials-Albums, Framing and Storage Materials; International Organization for Standardization: Geneva, Switzerland, 2013.

3. ISO 18911 Imaging Materials_Processed Safety Photographic Films_Storage Practices; International Organization for Standardization: Geneva, Switzerland, 2010.

4. EN 15757 Conservation of Cultural Property; British Standards Institution (BSI): London, UK, 2010.

5. PAS 198 Specification for Environmental Conditions for Cultural Collections; British Standards Institute: London, UK, 2012.

6. Schito, E.; Testi, D.; Grassi, W. Energy efficient methodologies for microclimate control in museum environments: A state of the art. In ASME-ATI-UIT 2015. Conference Proceeding Thermal Energy Systems: Production, Storage, Utilization and the Environment; Enzo Albano Editore: Napoli, Italy, 2015.

7. Camuffo, D. Microclimate for Cultural Heritage; Elsevier: Amsterdam, The Netherlands, 1998.

8. Bernardi, A. Preserving Artworks: Microclimate in Museum Environment; Il Prato: Padua, Italy, 2003.

9. Pavlogeorgatos, G. Environmental parameters in museums. Build. Environ. 2003, 38, 1457-1462.

10. Camuffo, D.; Bernardi, A. The Microclimate of Leonardo's Last Supper; Office for Official Pubs of the European Communities: Luxembourg, 1991; Volume 14, pp. 39-75.

11. Accardo, G.; Camuffo, D. Microclimate inside the Scrovegni Chapel in Padua. Stud. Conserv. 1980, $25,15-17$.

12. Bonacina, C.; Baggio, P.; Cappelletti, F.; Romagnoni, P.; Stevan, A.G. The Scrovegni Chapel: The results of over 20 years of indoor climate monitoring. Energy Build. 2015, 95, 144-152.

13. Boyes, N. Historic Scotland. In Aspects of Stone Weathering, Decay and Conservation; Imperial College Press: London, UK, 1999.

14. Rosslyn Chapel. Ongoing Care; Rosslyn Chapel: Roslin, UK, 2015. Available online: http://www. rosslynchapel.com/conservation/ongoing-care/ (accessed on 13 October 2016).

15. Bernardi, A.; Camuffo, D. Uffizi Galleries in Florence: A comparison between two different air conditioning systems. Sci. Technol. Cult. Herit. 1995, 4, 11-22.

16. Camuffo, D.; Bernardi, A.; Sturaro, G.; Valentino, A. The microclimate inside the Pollaiolo and Botticelli rooms in the Uffizi Gallery, Florence. J. Cult. Herit. 2002, 3, 155-161.

17. Camuffo, D.; Brimblecombe, P.; Van Grieken, R.; Busse, H.J.; Sturaro, G.; Valentino, A.; Bernardi, A.; Blades, N.; Shooter, D.; De Bock, L. Indoor air quality at the Correr museum, Venice, Italy. Sci. Total Environ. 1999, 236, 135-152.

18. Piccablotto, G.; Aghemo, C.; Pellegrino, A.; Iacomussi, P.; Radis, M. Study on conservation aspects using LED technology for museum lighting. Energy Procedia 2015, 78, 1347-1352.

19. Del Hoyo-Meléndez, J.M.; Mecklenburg, M.F.; Doménech-Carbó, M.T. An evaluation of daylight distribution as an initial preventive conservation measure at two Smithsonian Institution Museums, Washington DC, USA. J. Cult. Herit. 2011, 12, 54-64.

20. Tombazis, A.N.; Vratsanos, N.; Preuss, S.A. Guidelines for the design and retrofitting of energy-efficient museums for antiquities in the Mediterranean countries. In Proceedings of the ICOM Committee for Conservation, 12th Triennial Meeting, Lyon, France, 29 August-3 September 1999; James \& James: London, UK, 1999; Volume 1, pp. 106-112.

21. Tombazis, A.N.; Preuss, S.A. DG XII programme: Retrofitting of museums for antiquities in the Mediterranean countries. Energy Build. 2001, 33, 251-255.

22. Tombazis, A.N.; Blomsterberg, A.; Fisch, M.N.; Krainer, A.; Maldonado, E.; Mingozzi, A; Nordstrom, C. Museums-Energy Efficiency and Sustainability in Retrofitted and New Museum Buildings Handbook; University College Dublin: Dublin, Ireland, 2004; pp. 1-156.

23. Leissner, J.; Kilian, R.; Kotova, L.;Jacob, D.; Mikolajewicz, U.; Broström, T.; Ashley-Smith, J.; Schellen, H.L.; Martens, M.; Schijndel, J.V.; et al. Climate for culture: Assessing the impact of climate change on the future indoor climate in historic buildings using simulations. Herit. Sci. 2015, 3, 1.

24. FMS. Politecnico di Torino. In The Museum Building: Energy, Systems, Safety and Security; Saper Fare nei Musei: Florence, Italy, 2015. (In Italian) 
25. Rota, M.; Corgnati, S.P.; Di Corato, L. The Museum in Historical Buildings: Energy and Systems. The Project of the Fondazione Musei Senesi. In Proceedings of the 49th AiCARR International Conference, Rome, Italy, 26-28 Febuary 2014.

26. Sciurpi, F.; Carletti, C.; Cellai, G.; Pierangioli, L. Environmental monitoring and microclimatic control strategies in “La Specola" museum of Florence. Energy Build. 2015, 95, 190-201.

27. Kramer, R.; van Schijndel, A.W.M.; Schellen, H.L. Energy conservation in museums via setpoint strategies: A case study for a state-of-the-art museum using building simulations. Appl. Energy 2014, 158, 446-458.

28. Brimblecombe, P.; Blades, N.; Camuffo, D.; Sturaro, G.; Valentino, A.; Gysels, K.; Grieken, R.; Busse, H.J.; Kim, O.; Ulrych, U. The indoor environment of a modern museum building, the Sainsbury Centre for Visual Arts, Norwich, UK. Indoor Air 1999, 9, 146-164.

29. Gysels, K.; Delalieux, F.; Deutsch, F.; Van Grieken, R.; Camuffo, D.; Bernardi, A.; Sturaro, G.; Busse, H.J.; Wieser, M. Indoor environment and conservation in the royal museum of fine arts, Antwerp, Belgium. J. Cult. Herit. 2004, 5, 221-230.

30. Costanzo, S.; Cusumano, A.; Giaconia, C.; Giaconia, G. Preservation of the artistic heritage within the seat of the Chancellorship of the University of Palermo: A proposal on a methodology regarding an environmental investigation according to Italian Standards. Build. Environ. 2006, 41, 1847-1859.

31. Van Schijndel, A.W.M.; Schellen, H.L.; Wijffelaars J.L.; van Zundert, K. Application of an integrated indoor climate, HVAC and showcase model for the indoor climate performance of a museum. Energy Build. 2008, 40, 647-653.

32. American Society of Heating, Refrigerating and Air-Conditioning Engineers (ASHRAE). ASHRAE Handbook: Heating, Ventilating and Air-Conditioning Applications Museums, Libraries and Archives; ASHRAE: Atlanta, GA, USA, 2003; Volume 203, Chapter 21.

33. Centro Studi Piemontesi Management and Preservation of Museums, Guidelines for Museums; L'Artistica Savigliano: Turin, Italy, 2007. (In Italian)

34. Corgnati, S.P.; Fabi, V.; Filippi, M. A methodology for microclimatic quality evaluation in museums: Application to a temporary exhibit. Build. Environ. 2009, $44,1253-1260$.

35. Corgnati, S.P.; Filippi, M. Assessment of thermo-hygrometric quality in museums: Method and in-field application to the "Duccio di Buoninsegn" exhibition at Santa Maria della Scala (Siena, Italy). J. Cult. Herit. 2010, 11, 345-349.

36. D'agostino, V.; d'Ambrosio Alfano, F.R.; Palella, B.I.; Riccio, G. The museum environment: A protocol for evaluation of microclimatic conditions. Energy Build. 2015, 95 ,124-129.

37. Huijbregts, Z.; Kramer R.P.; Martens, M.H.J.; van Schijndel, A.W.M.; Schellen, H.L. A proposed method to assess the damage risk of future climate change to museum objects in historic buildings. Build. Environ. 2012, 55, 43-56.

38. Thomson, G. The Museum Environment; Elsevier: Amsterdam, The Netherlands, 1986.

39. Testi, D.; Schito, E.; Menchetti, E.; Grassi, W. Energy retrofit of an office building by substitution of the generation system: Performance evaluation via dynamic simulation versus current technical standards. J. Phys. Conf. Ser. 2014, 547, doi:10.1088/1742-6596/547/1/012018.

40. Testi, D.; Schito, E.; Tiberi, E.; Conti, P.; Grassi, W. Building Energy Simulation by an In-house Full Transient Model for Radiant Systems Coupled to a Modulating Heat Pump. Energy Procedia 2015, 78, 1135-1140.

41. Ferdyn-Grygierek, J. Indoor environment quality in the museum building and its effect on heating and cooling demand. Energy Build. 2014, 85, 32-44.

42. Silva, H.E.; Henriques, F.M.A.; Henriques, T.A.S.; Coelho, G. A sequential process to assess and optimize the indoor climate in museums. Build. Environ. 2016, 104, 21-34.

43. Kramer, R.P.; Schellen, H.L.; van Schijndel, A.W.M. Impact of ASHRAE's museum climate classes on energy consumption and indoor climate fluctuations: Full-scale measurements in museum Hermitage Amsterdam. Energy Build. 2016, 130, 286-294.

44. Moffat, R.J. Describing the uncertainties in experimental results. Exp. Therm. Fluid Sci. 1988, 1, 3-17.

(C) 2016 by the authors; licensee MDPI, Basel, Switzerland. This article is an open access article distributed under the terms and conditions of the Creative Commons Attribution (CC-BY) license (http:/ / creativecommons.org/licenses/by/4.0/). 